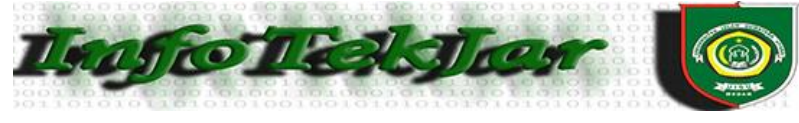

\title{
MOSELE : APLIKASI MOBILE LEARNING BUDIDAYA LELE SISTEM TERPAL BERBASIS ANDROID
}

\author{
Novita Indah Pramudita ${ }^{1}$, Herman Yuliansyah ${ }^{2}$ \\ Program Studi Teknik Informatika Fakultas Teknologi Industri \\ Universitas Ahmad Dahlan Yogyakarta, Jl. Prof. Dr. Soepomo \\ Janturan, 55164 \\ 1) nozhbitha@gmail.com, ${ }^{2)} \underline{\text { Herman.yuliansyah@ tif.uad.ac.id }}$
}

\begin{abstract}
Abstrak-Budidaya lele merupakan jenis usaha yang jika tidak direncanakan dengan matang, akan sangat merugikan usaha. Ada beberapa tahap yang perlu diperhatikan dalam merencanakan usaha budidaya lele, yaitu penyusunan jadwal kegiatan, menetapkan fasilitas fisik, dan menentukan spesifikasi pekerjaan. Dalam hal ini yang paling penting adalah penjadwalan kegiatan, karena dalam proses ternak lele memerlukan banyak proses dalam pemeliharaannya yaitu proses pembuatan kolam, pemilihan bibit, peneberan bibit, pemberian pakan, dan jadwal panen. Dalam hal ini, pendampingan budidaya lele oleh Petugas Pendamping Ternak sangat penting untuk membantu peternak dalam melakukan proses kegiatan budidaya lele. Di Posdaya lele sanden, para peternak yang tergabung dalam anggota ternak berdomisili di dusun- dusun kawasan sanden, sehingga Petugas Pendamping Ternak (PPT) merasa kesulitan dalam melakukan proses pendampingan ternak. Saat ini proses pendampingan ternak masih dilakukan dengan cara datang langsung ke lokasi budidaya lele. Masalah tersebut dapat diatasi dengan Aplikasi Mobile yang sedang dikembangkan. Agar penyampaian informasi mengenai jadwal kegiatan ternak dapat dilakukan dengan mudah maka dibutuhkan Web Service yang mampu mengirim jadwal kegiatan ternak secara otomatis berupa Push Notification yang dikirim ke Aplikasi Mobile.

Metodologi yang digunakan dalam penelitian ini yaitu melakukan pengumpulan data menggunakan metode wawancara dan observasi. Kemudian dianalisis untuk menentukan kebutuhan user dan kebutuhan sistem. Implementasi aplikasi memanfaatkan Java Android. Pengujian sistem dilakukan dengan metode Blackbox Test.

Hasil dari penilitian ini adalah Aplikasi Mobile yang digunakan oleh Peternak sebagai media untuk menerima notifikasi berupa informasi jadwal kegiatan budidaya lele.
\end{abstract}

Kata Kunci : mobile learning, android, mobile, Learning, budidaya lele terpal, Aplikasi Mobile, Web Service, Push Notification, Android Cloud To Device Messaging.

\subsection{Latar Belakang Masalah}

\section{PENDAHULUAN}

Ikan lele merupakan salah satu komoditas air tawar yang banyak dibudidayakan dan digemari oleh sebagian besar masyarakat di wilayah

Yogyakarta. Peluang pasar ikan lele di Yogyakarta cukup besar, jika ditekuni dan dilakukan dengan benar, budidaya ikan lele akan menghasilkan keuntungan dan keunggulan yang sangat besar bagi peternak lele. Hal tersebut dikarenakan stabilnya permintaan pasar baik benih lele maupun konsumsinya yang terus meningkat terutama yang diserap oleh warung pecel lele, namun selain itu supermarket, restoran, dan rumah makan membutuhkan pasokan lele yang cukup tinggi dan kontinyu. Untuk memulai usaha budidaya lele yang sukses peternak lele harus memiliki mindset yang benar bahwa keberhasilan disektor pertanian khususnya jenis ternak tidak instan karena peternak lele pemula harus dapat meningkatkan metode budidaya lele. Untuk itu sebelum membudidayakan lele, para peternak lele pemula harus memiliki pengetahuan dasar mengenai budidaya ikan lele (Taufik, 2010)

Dalam budidaya lele sebenarnya tidak memerlukan teknik khusus, yang di perlukan adalah kolam dan pakan yang cukup. Belakangan mulai dikenal teknik budidaya lele dengan mengunakan kolam terpal. Budidaya ikan lele dengan media kolam terpal saat ini menjadi pilihan paling favorit dibandingkan dengan media yang lain karena lebih ringkas, praktis, hemat dan lebih mudah dikontrol, serta mudahnya media dan bahan yang dibutuhkan untuk membudidayakan ikan ini tanpa harus memiliki lahan yang luas (Nasrudin,2010).

Budidaya lele pada sistem terpal ini memiliki tahapan-tahapan yang harus di lakukan yaitu penyiapan lahan, pembuatan kolam, pemilihan bibit, penebaran bibit, pendederan dan pemijahan serta diperlukan manajemen pakan dan manajemen air yang harus benar-benar diperhatikan oleh peternak lele khususnya bagi peternak pemula. Oleh karena itu pengetahuan akan teknologi budidaya, tahapan budidaya dan pengetahuan akan tempat serta air dan pakan ikan lele akan sangat penting dalam membantu kesuksesan ternak lele (Zubir, 2006).

Berdasarkan wawancara yang dilakukan dengan Bapak Fajar santoso selaku Dukuh dusun Demangan dan salah satu peternak lele di dusun Demangan Gadingsari Sanden Bantul pada tanggal 28 September 2015 didapatkan informasi bahwa sebagian besar peternak lele mendapatkan pengetahuan budidaya lele oleh kelompok usaha tani dan melalui usaha mandiri (belajar mandiri) selain itu dengan mengundang seorang pakar/ pembudidaya lele yang telah berhasil mengembangkan budidaya lele. Dalam mengundang ahli memerlukan biaya sehingga peternak lele lebih memilih untuk belajar mandiri seperti menggunakan buku ataupun 
tutorial. Belajar menggunakan buku dirasakan kurang efisien karena dalam hal ini praktik langsung akan lebih efisien. Namun dalam praktiknya peternak lele pemula terkadang melupakan jadwal- jadwal dalam budidaya lele seperti jadwal penaburan benih, pemberian pakan, jadwal mengganti air kolam sehingga membuat hasil budidaya lele kurang maksimal.

Peternak lele mengharapkan adanya aplikasi android yang dapat membantu pekerjaan mereka dan memecahkan masalah yang selama ini mereka hadapi dalam budidaya lele setelah mengetahui apa itu android dan mobile learning serta manfaat yang diberikan oleh teknologi tersebut. Aplikasi android Mobile Learning sangat sesuai untuk diterapkan dengan mengetahui masalah yang selama ini terjadi disana. Peternak yang selama ini hanya mencari bahan ajar dengan cara bertanya dan otodidak, mencari sumber pembelajaran budidaya dengan memanggil pakar, tetapi pada praktiknya masih kesulitan dalam proses budidaya. Peternak dapat dengan mudah mengetahui cara budidaya ikan lele tersebut dengan aplikasi android mobile learning yang akan dikembangkan.

Berdasarkan latar belakang diatas, maka dikembangkanlah Aplikasi Mobile Learning Budidaya Lele Sistem Terpal Berbasis Android yaitu Aplikasi monitoring budidaya lele sistem terpal menggunakan notification berbasis firebase cloud messaging yang dapat memberikan solusi dari permasalahan dalam mencari cara budidaya lele seperti pembuatan kolam, pembibitan dan pemijahan, jadwal peternak, dll. Jika aplikasi ini diterapkan, peternak akan mendapatkan sebuah alat bantu dalam melakukan budidaya lele tentang jadwal budidaya lele sehingga peternak tidak lupa mengenai jadwal budidaya karena aplikasi ini memiliki sistem notifikasi sebagai pengingat jadwal budidaya lele mulai dari tanggal penaburan benih, jadwal pemberian pakan serta memonitoring setiap hasil budidaya lele dengan output berupa grafik yang dapat dilihat setelah masa panen.

\section{KAJIAN PUSTAKA}

Dari penelitian yang dilakukan tentang aplikasi mobile learning budidaya lele lahan kering sistem terpat (lelaki sintal) berbasis android, permasalahan yang terjadi adalah peternak lele tidak mampu untuk membayar pakar untuk memberi pembelajaran mengenai budidaya ikan lele. Meskipun sudah banyak tutorial dan buku mengenai budidaya ikan yang di buat untuk memudahkan peternak lele pemula dalam membudidayakan ikan lele, tetapi pada praktiknya peternak masih melakukan cara budidaya lele dengan otodidak, mereka merasa membaca buku membuat jenuh dan bosan. Berdasarkan permasalahan tersebut, aplikasi ini dikembangkan dengan tujuan untuk memberikan sebuah media pembelajaran interaktif mengenai budidaya ikan lele lahan kering sistem terpal sehingga bisa membantu dan bisa meningkatkan efektivitas serta gairah belajar mereka dalam membudidayakan lele. Aplikasi mobilelearning budidaya lele lahan kering sistem terpal ini menggunakan Firebase yaitu BaaS (Backend as a Service) yang merupakan layanan mobile yang dikembangkan oleh Google yang memungkinkan pengembang untuk mengirim data pemberitahuan atau informasi dari server pengembang dari ke aplikasi yang menargetkan Android Sistem Operasi Google. Dua fitur yang menarik adalah Firebase Remote Config dan Firebase Real Time Database farebase tersedia untuk pengembang gratis.

Data yang di jadikan sebagai sebuah persyaratan kebutuhan didapatkan dari wawancara kepada dinas kelautan dan perikanan daerah istimewa Yogyakarta serta kuisioner kepada peternak lele pemula. Hasil dari penelitian yang dilakukan adalah dihasilkannya sebuah aplikasi mobile learning budidaya lele lahan kering sistem terpal untuk membantu dan meningkatkan gairah belajar budidaya lele yang benar untuk para peternak lele pemula.

\subsection{Budidaya lele Sistem Terpal}

Budidaya lele kolam terpal merupakan salah satu jenis budidaya ikan lele di indonesia yang ekonomis, dan relatif lebih mudah dan murah dalam teknik budidayanya karena tidak memerlukan persyaratan khusus tempat atau kolam pemeliharaan (Khoiruman, 2009).

Adapun kelebihan budidaya lele kolam terpal antara lain
a. Tidak memerlukan lahan yang luas.
b. Lebih flexibel (kolam dapat dipindah).
c. Perawatan kolam lebih mudah.
d. Biaya pembuatan dapat diminimalisir.
e. Lele hasil budidaya tidak berbau lumpur

\subsection{Android}

Android adalah sebuah sistem operasi untuk perangkat mobile berbasis linux yang mencakup sistem operasi, middleware, dan aplikasi. Android menyediakan platform terbuka bagi para pengembang untuk menciptakan aplikasi mereka. Android dipuji sebagai platform mobile pertama yang lengkap, terbuka, dan bebas. Lengkap karena android merupakan sistem operasi yang aman dan banyak menyediakan tools dalam membangun software dan memungkinkan untuk peluang pengembangan aplikasi. Terbuka karena pengembang dapat dengan bebas untuk mengembangkan aplikasi. Dan bebas karena tidak ada lisensi atau biaya royalty untk dikembangkan pada platform Android (Safaat H, 2012).

\subsection{Firebase Cloud Messaging}

Firebase Cloud Messaging (sering disebut sebagai FCM) adalah layanan DbaaS (Database as a Service) dengan konsep realtime. Tidak hanya numpang simpan data, kita juga di sediakan API untuk implementasi web socket. Firebase menyediakan library untuk berbagai client platform. Kita tinggal pakai saja. Browser pakai Javascript API dan mobile pakai OBJ-C atau Android API.

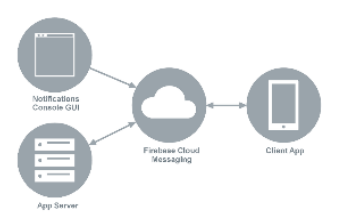

Gambar 3.1 Alur Kerja FCM (Firebase Cloud Messaging)

Penjelasan alur kerja FCM sebagai berikut: 
1. Pertama device Android mengirimkan id pengirim dan id aplikasi ke server FCM untuk registrasi.

2. Apabila registrasi berhasil, server FCMakan menerbitkan id registrasi kepada device Android.

3. Setelah mendapatkan id registrasi, device akan mengirimkan id registrasi ke server.

4. Server akan menyimpan id registrasi pada database untuk penggunaan selanjutnya.

5. Setiap kali notifikasi push dibutuhkan, server akan mengirimkan pesan ke server FCM beserta id registrasi devicenya.

6. Server FCMakan mengirimkan pesan ini ke device Android yang bersangkutan menggunakan id registrasi.

\subsection{Mobile Learning}

Istilah mobile learning (m-learning) mengacu kepada penggunaan perangkat IT genggam dan bergerak, seperti PDA, telepon genggam, laptop dan tablet PC, dalam pengajaran dan pembelajaran (M. Ally, Dkk, 2005). Mlearning adalah pembelajaran yang unik karena pembelajar dapat mengakses materi pembelajaran, arahan dan aplikasi yang berkaitan dengan course kapanpun dan dimana-pun. Hal ini akan meningkatkan perhatian pada materi pembel ajaran, membuat pembelajaran menjadi pervasif, dan dapat mendorong motivasi pembelajar kepada pembelajaran sepanjang hayat (lifelong learning). Selain itu, dibandingkan pembelajaran konvensional, m-learning memungkinkan adanya lebih banyak kesempatan untuk kolaborasi secara adhoc dan berinteraksi secara informal diantara pembelajar (Yonatan Andy, 2007).

Mobile learning atau m-learning sering didefinisikan sebagai e-learning melalui perangkat komputasi mobile (Yonatan Andi, 2007). M-learning merupakan penyampaian bahan pembelajaran elektronik pada alat komputasi mobile agar dapat diakses dari mana saja dan kapan saja. Pada umumnya, perangkat mobile yang dimaksud berupa handphone dan PDA (M. Ally, Dkk, 2005).

\subsection{Objek Peneitian}

\section{METODE PENELITIAN}

Objek penelitian terkait dengan tugas akhir yang berjudul "Mosele: Aplikasi Mobile Learning Budidaya Lele Sistem Terpal Berbasis Android" adalah manajemen ternak yang dilakukan oleh Petugas Pendampingan Ternak dan komunikasi serta pemantauan secara otomatis melalui aplikasi web mobile mengenai proses Budidaya lee sistem terpal. Alasan untuk memilih Posdaya lele Sanden sebagai objek penelitian adalah perlunya sebuah Aplikasi berbasis MobileSmartphone agar proses penyebaran Informasi dari Petugas Pendamping Ternak (PPT) kepada peternak lele lebih cepatdan tepat tanpa harus datang ke lokasi peternakan. Aplikasi Mobile ini diharapkan peternak dapat menerima Informasi dari Petugas Pendampingan Ternak secara realtime dan Petugas Pendampingan Ternak lebih mudah dan cepat dalam melakukan proses Budidaya lele. Metode Pengumpulan Data

Dalam mengambil beberapa data yang dibutuhkan dalam pembuatan Aplikasi MOSELE menggunakan beberapa metode sebagai berikut :

1. Metode Observasi

Metode observasi dilakukan dengan cara melakukan pengamatan secara langsung di Kantor Posdaya lele Sanden dan dilanjutkan dengan pengamatan secara cermat dan sistematis sesuai dengan kondisi yang sebenarnya. Seperti pengamatan pada proses pendampingan ternak lele yang dilakukan oleh Petugas Pendampingan Ternak (PPT) di lokasi peternakan.

2. Metode Wawancara

Metode wawancara dilakukan dengan mengadakan tanya jawab kepada Kepala Posdaya lele Sanden yaitu Fajar Santosa, mengenai permasalahan yang ada pada saat proses pendampingan ternak terutama untuk pendampingan ternak kepada peternak yang berada di luar wilayah Sanden.

3.2 Alat dan Bahan

1. Perangkat Keras (Hardware)

Perangkat keras (hardware) yang digunakan dalam Aplikasi MOSELE antara lain :

3.2.1.1.1 Laptop dengan spesifikasi :

1) Intel ${ }^{\circ}$ Core i3 Processor $2.4 \mathrm{GHz}, 3 \mathrm{MB} \mathrm{L} 3$ Cache

2) RAM 6GB DDR3

3) 500GB SATAII $5400 \mathrm{RPM}$

4) AMD RadeonTM HD6470M

5) Smartphone Android

2. Perangkat Lunak (Software)

Perangkat lunak (software) yang digunakan dalam pembuatan Aplikasi MOSELE antara lain :

a. Sistem Operasi : Windows 10, OS Android

b. Bahasa Pemrograman : JAVA, Android, XML

c. Case Tools :Android Studio, Astah Profesional, Justinmind Prototyper, , Corel Draw, Photoshop.

\subsection{Analisis Kebutuhan}

Kegiatan dalam tahap ini adalah menganalisis kebutuhan untuk membangun Aplikasi MOSELE untuk peternak Lele di Posdaya lele Sanden. Kegiatan analisis sistem yang dilakukan mencakup kebutuhan fungsional, kebutuhan nonfungsional, dan use case diagram. Hasil dari analisis kebutuhan sistem ini dijadikan sebagai dasar untuk menentukan spesifikasi sistem pencarian yang akan dikembangkan adalah sebagai berikut :

1. Kebutuhan Fungsional

Kebutuhan fungsional adalah kebutuhan untuk system menggambarkan apa yang sistem yang harus lakukan (Sommerville, 2007). Aplikasi yang akan dibangun ini memiliki beberapa fungsionalitas antara lain membantu penjadwalan budidaya lele, pemberian referensi bahan ajar budidaya lele, dan dokumentasi penjualan hasil panen lele berupa grafik sehingga proses Budidaya lele yang dilakukan oleh Peternak lele akan lebih mudah.

2. Kebutuhan Non-Fungsional

Kebutuhan non fungsional adalah Kebutuhan yang tidak langsung berkaitan dengan fungsi-fungsi khusus yang disampaikan oleh sistem (Sommerville, 2007). Pembuatan 
Aplikasi MOSELEmenghasilkan media informasi jadwal kegiatan ternak yang di kirim ke perangkat mobile peternak.

3. Use Case Diagram

Kegiatan yang dilakukan pada tahap ini adalah merancang sistem menggunakan UML dan merancang antarmuka (user interface).

a. Perancangan sistem menggunakan use case diagram untuk menggambarkan kebutuhan useryaitu peternak lele. Untuk menggambarkan relasi antar object dan class di dalam sistem tersebut menggunakan class diagram.

b. Perancangan antarmuka meliputi struktur menu, input dan output pada halaman-halaman untuk bagian user agar nyaman digunakan.

3.4 Perancangan Sistem

a. Perancangan Basis Data

Perancangan basis data digunakan untuk menggambarkan model data yang ada pada sistem yang akan dikembangkan dan untuk menggambarkannya digunakan classdiagram yang bertujuan untuk menggambarkan relasi antar objek dan class yang ada dalam sistem.

b. Perancangan Antarmuka

Perancangan antarmuka bertujuan untuk memberikan gambaran aplikasi kepada user. Perancangan antar muka meliputi struktur menu, input dan output aplikasi, dan fungsi - fungsi yang ada di dalam aplikasi (terlampir).

c. Arsitektur Sistem

Arsitektur sistem yang dibangun terdiri dari 3 komponen yaitu:

\section{Mobile Device}

Perangkat yang menjalankan aplikasi Android yang menggunakan C2DM. Ini harus perangkat Android yang memiliki Market yang sudah terinstal, dan harus memiliki minimal satu login akun Google.

\section{Application Server}

Server aplikasi yang sudah pengembang tetapkan sebagai bagian dari pelaksanaan C2DM dalam aplikasi mereka. Server aplikasi pihak ketiga mengirim data ke aplikasi Android pada perangkat melalui server $C 2 D M$.

\subsection{Implementasi}

Tahap ini akan menerjemahkan design yang telah dibuat pada point 2 ke dalam bahasa pemrograman. Bahasa pemrograman yang digunakan untuk membangun aplikasi inti adalah Java, sedangkan database nya menggunakan MySQL.

3.6 Pengujian Sistem

Untuk melakukan pengujian sistem ini dibangun dilakukan dengan menggunakan metode pengujian Usability. Pengujian Usability adalah pengujian yang dilakukan setelah user menggunakan sistem secara menyeluruh. Metode yang digunakan adalah SUS (Software Usability Scale). Pengujian dilakukan dengan memberikan kuisioner yang terdiri dari 10 item pertanyaan, dengan menggunakan skala likert 5 tingkat. Item ganjil memiliki lima pertanyaan positif dan item genap memiliki 5 pertanyaan negatif. Dengan kontribusi nilai dari masing-masing item pertanyaan adalah 0-5.

\section{HASIL DAN PEMBAHASAN}

4.1 Hasil Pengumpulan Data

Berdasarkan hasil pengumpulan data yang telah dilakukan di Posdaya lele Sanden. Diperoleh data-data yang bisa dijadikan untuk mendukung penelitian. Datadata tersebut diantaranya adalah sebagai berikut:

Dari hasil observasi yang telah dilakukan di Posdaya lele Sanden diperoleh data tentang Pembuatan Kolam, penebaran bibit, takaran pakan lele dan jenis pakan yang diberikan selama proses budidaya lele berlangsung yaitu:

1. Kolam terpal dibuat dan disterilkan menggunakan pelepah pisang selama 3 hari setelah itu dilakukan penebaran bibit lele.

2. Takaran dan Jenis Pakan lele pada hari ke 1-13 Hari (Starter) adalah pakan alami yaitu cacing sutra dan uget-uget atau pelet lele. Pemberian pakan dilakukan 4x sehari yaitu pukul : 09.00, 13.00, 17.00, 21.00.

3. Takaran dan Jenis Pakan jangkrik pada hari ke 14-59 Hari (Finisher) adalah pakan apung sebanyak 1 ember kecil. Pemberian pakan dilakukan $4 \mathrm{x}$ sehari yaitu pukul : 09.00, 13.00, 17.00, 21.00.

4. Takaran dan Jenis Pakan jangkrik pada hari ke 60- 72 Hari (Finisher) adalah pakan tenggelam dan pakan tambahan berupa ayam tiren atau ikan runcah. Pemberian pakan dilakukan $4 \mathrm{x}$ sehari yaitu pukul : 09.00, 13.00, 17.00, 21.00 .

5. Pada Usia 75 Hari lele sudah memasuki masa panen, yaitu dengan panjang lele dipasaran $25-26 \mathrm{~cm}$.

4.2 Analisis Kebutuhan

Pada tahap ini dilakukan analisis system berdasarkan hasil pengumpulan data yang dilakukan untuk membangun Aplikasi Mosele berbasis android. Analisis kebutuhan sistem yang dilakukan mencakup kebutuhan user dan kebutuhan sistem.

a. Kebutuhan User

1.Peternak lele dapat Login pada Aplikasi di perangkat Mobile

2.Petani lele dapat menerima informasi jadwal kegiatan dalam proses budidaya lele

3.Petani lele dapat melihat history dari informasi mengenai jadwal kegiatan dalam proses ternak

4.Petani lele dapat melihat grafik perbandingan penjualan lele

5.Petani dapat menambahkan kolam budidaya lele

b. Kebutuhan Sistem

Analisis sistem yang dilakukan mencakup kebutuhan terkait fungsional, kebutuhan terkait non-fungsional dan use case.

1. Kebutuhan Fungsional

- Masuk ke Sistem Aplikasi Mobile

Sistem akan mengijinkan User untuk masuk ke system jika username dan password yang diinputkan benar.

- Notifikasi jadwal kegiatan budidaya lele

Sistem akan menampilkan notifikasi jadwal kegiatan budidaya lele berupa suara dan text pada 
Aplikasi Mobile.

- Notification History

Sistem akan menampilkan menu NotificationHistory pada Perangkat Mobile apabila Notifikasi yang muncul belum dibaca oleh User.

- Penjualan Lele

Sistem akan menampilkan grafik penjualan lele yang dijual melalui Posdaya lele Sanden berdasarkan jumlah pembelian bibit dan jumlah hasil panen lele

- Tambah kolam lele

Sistem akan menampilkan tombol tambah kolam lele yang dapat digunakan petani untuk menambahkan kolam lele baru.

- Keluar dari system Aplikasi Mobile

Sistem akan mengijinkan User untuk keluar dari sistem.

2.Kebutuhan Non Fungsional

- Operational

Aplikasi Mosele berbasis android menggunakan Metode Firebase Cloud Messaging membutuhkan koneksi internet agar bisa berjalan. Ukuran aplikasi Aplikasi adalah 4 MB dan kecepatan penyimpanan datanya kurang lebih 1 menit. Tampilan notifikasi jadwal kegiatan budidaya lele adalah menggunakan model PushNotifications.

\section{- Security}

Semua password

dilindungi secara enkripsi. Hanya User yang sudah terdaftar yang dapat menggunakan

\section{UseCase}

Aplikasi Mobile pendampingan budidaya lele.

Use case diagram digunakan untuk menggambarkan proses yang dapat dilakukan oleh user. Pembuatan usecase ini didasarkan pada analisis kebutuhan fungsional Aplikasi Mosele berbasis android Menggunakan Metode Firebase Cloud Messaging.

Gambar 4.1 merupakan UseCase Diagram pada Aplikasi Mobile Learning Budidaya Lele Sistem Terpal Berbasis Android. Terdapat 1 klasifikasi user, yaitu petani lele.

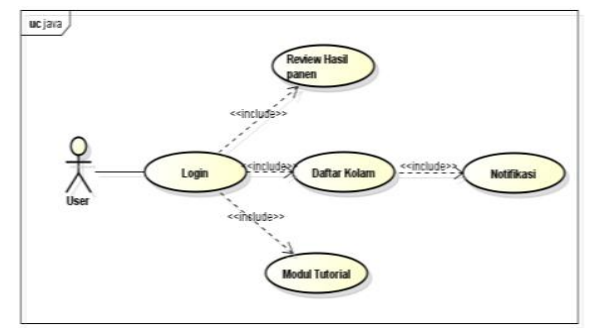

Gambar 4.1: Use Case Diagram

\subsection{Perancangan Sistem}

Perancangan sistem merupakan tahap selanjutnya setelah analisis sistem. Perancangan sistem digunakan untuk mendapatkan gambaran tentang apa yang dikerjakan pada analisis sistem untuk membentuk sistem tersebut. Berikut ini adalah perancangan sistem Aplikasi Mobile Learning Budidaya Lele Sistem Terpal Berbasis Android.

a. ActivityDiagram

ActivityDiagram digunakan untuk menggambarkan proses bisnis dan urutan aktivitas dalam sebuah proses. Berikut ini activity diagram yang ada pada sistem Aplikasi Mosele Berbasis Android.

b. Entity Relational Diagram (ERD)

Entity Relational Diagram (ERD) digunakan untuk memodelkan struktur data dan hubungan antar data. ERD juga digunakan untuk merancang basis data pada aplikasi web pendampingan ternak jangkrik.

c. Mapping Table

Setelah merancang model basis data dengan ERD tahap selanjutnya adalah memetakan entitas atau relasinya kedalam sebuah tabel. Mapping table mempunyai ketentuan yaitu setiap entitas pasti berubah menjadi tabel serta atributnya akan menjadi field dari tabel tersebut. Sedangkan relasi bisa berubah menjadi tabel dan bisa juga tidak. Berdasarkan ERD yang telah dibuat, kardinalitas yang dihasilkan dari semua relasi yang ada adalah 1 - $\mathrm{N}$ (one to many) sehingga relasi tidak menjadi tabel, melainkan dilakukan penambahan primary key dari entitas dengan kardinalitas 1 ke entitas dengan kardinalitas $\mathrm{N}$.

d. Struktur Tabel

Basis data pada Aplikasi Mosele Berbasis Android terdiri dari beberapa tabel yang digunakan di android maupun di website.

e. Implementasi

\section{f. Halaman Login}

UsecaseLogin berisi proses yang menampikan form login dan activtyproses login hingga menampikan dashboard.

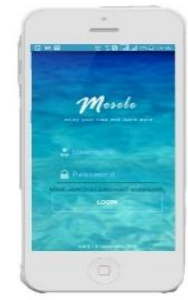

Gambar 4.2: Halaman Login Aplikasi Mobile

g. Notifikasi

Noifikasi berisi proses yang menampikan push notifikasi firebase ke perangkat android 


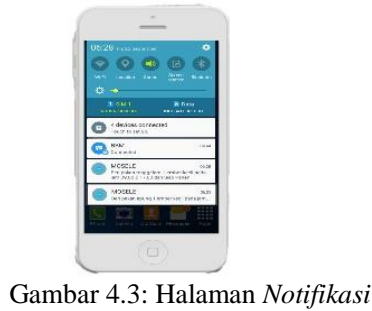

h. Pengujian

Setelah Penulis mencoba sistem, maka diberikan kuesioner untuk di isi untuk menguji post study. Dan hasil dari kuesioner tersebut terpaparkan pada table rekapitulasi jawaban penulis .

Pertanyaan urutan ganjil (bernada positif), skor dihitung pada skala posisi dikurangi/minus 1 (xi-1). Pertanyaan urutan genap (bernada negatif), skor dihitung pada 5 dikurangi/minus skala posisi (5-xi) Skor SUS keseluruhan didapat dengan mengkalikan kontribusi skor item dengan 2.5. Sehingga skor SUS keseluruhan berada pada range $0 . .100$ dengan penambahan atau inkremental setiap 2.5 poin.

Total Score SUS adalah :

Jumlah skor yang di dapatkan dari semua responden

JumlahskorYangdidapatkandarisemuaresponden. JumlahResponden

Didapatkan skor 89.58 (dengan sekala $0 . .100$ )

Tabel 4. 10 Tabel Kategori Rentan Skor SUS

\begin{tabular}{|c|l|l|l|l|}
\hline $\begin{array}{l}\mathrm{N} \\
\mathrm{o}\end{array}$ & Kategori & $\begin{array}{l}\text { Renta } \\
\text { ng } \\
\text { Skor }\end{array}$ & $\begin{array}{l}\text { Jum } \\
\text { lah }\end{array}$ & $\begin{array}{l}\text { Pre } \\
\text { sen } \\
\text { tase }\end{array}$ \\
\hline 1 & $\begin{array}{l}\text { Not } \\
\text { Accepta } \\
\text { ble }\end{array}$ & $\begin{array}{l}0- \\
50\end{array}$ & 0 & $0 \%$ \\
\hline 2 & Marginal & $\begin{array}{l}51- \\
70\end{array}$ & 0 & $0 \%$ \\
\hline 3 & $\begin{array}{l}\text { Accepta } \\
\text { ble }\end{array}$ & $\begin{array}{l}71- \\
100\end{array}$ & 30 & $100 \%$ \\
\hline
\end{tabular}

$100 \%$ responden menyatakan sistema aplikasi bisa diterima (acceptable). Artinya berdasarkan rerata penilaian SUS responden sebesar 89,58 sistem aplikasi dinyatakan aceptable

\subsection{Kesimpulan}

\section{KESIMPULAN DAN SARAN}

Berdasarkan hasil penelitian yang telah dilakukan pada Aplikasi Mosele : Mobile Learning Budidaya Lele Sistem terpal berbasis Android dapat disimpulkan bahwa :

1. Telah dibangun System yang mampu mengirim Notifikasi jadwal proses kegiatan ternak secara otomatis dan mampu menerima feedback dari peternak mengenai pelaksanaan jadwal proses kegiatan ternak sehingga proses penyampaian dan penerimaan informasi jadwal proses kegiatan ternak dapat dilakukan kapanpun dan dimanapun.

2. Adanya Fitur Grafik perkembangan hasil panen agar peternak dapat melihat secara detail mengenai A. Saran perkembangan ternak mereka.

Pengembangan Aplikasi Mobile pada penelitian ini masih memiliki keterbatasan, maka diharapkan adanya pengembangan dimasa mendatang. Berikut beberapa saran yang dikemukakan terkait dengan penelitian pada Aplikasi Mobile ini adalah diharapkan adanya pengembangan fitur pembelian pakan ternak serta alat dan bahan dalam budidaya lele, sehingga memudahkan peternak dalam mendapatkan kebutuhan budidaya lele.

\section{REFERENSI}

[1] Taufik. 2010. Analisis pendapatan Usaha Tani dan Penanganan Pasca Panen. Balai Budidaya Air Tawar. Sukabumi

[2] Zubir. 2006. Studi kelayakan Usaha. Fakultas Ekonomi Universitas Indonesia. Jakarta

[3] Sudana, S.N., Arga, I.W., Suparta, N. 2013. Kelayakan Usaha Budidaya lele Dumbo (Clarias gariepinus) dan pengaruhnya Terhadap Tingkat Pendapatan Petani Ikan Lele di Kabupaten Tabanan. J. Manajemen Agribisnis. 1(1)

[4] Nasrudin. 2010. Jurus Sukses Beternak lele Sangkuriang. PT Penebar Swadaya. Jakarta

[5] Jaja., Suryani, A., Sumantadinata, K. 2013. Usaha Pembesaran dan Pemasran Ikan Lele Serta Strategi Pengembangannya di UD sumber Rezeki Parung. Jawa Barat. J. Ipb.id.8(1) :45-56

[6] Google. (2012, September 26). Android Cloud to Device Messaging Framework-Android Google Developers. Retrieved Januari 6, 2015, from Android Google Developers: https://developers.google.com/android/c2dm/

[7] Kato, B., 2013. Kelebihan Android - Keuntungan Memiliki Ponsel Android.

[8] Safaat H, N., 2012. Android Pemrograman Aplikasi Mobile Smartphone dan Tablet PC Berbasis Android. Informatika, Bandung. 